\title{
Conversion of Physics-Based Labs to an Engineering Physics Curriculum
}

\author{
Theodore D. Thiede and James M. Hereford \\ Department of Physics and Engineering \\ Murray State University \\ Murray, KY 42071
}

\begin{abstract}
In recent times there has been a shift of enrollment of undergraduates from more traditional, research-oriented physics curricula toward more general, applied, engineering physics curricula. As part of this process, the emphasis of activities in undergraduate laboratories must shift from a sole focus on understanding physical phenomena to include a focus on providing the tools and experiences that will allow graduates to apply experimental methods in the development of new processes and products. In a larger, research-oriented engineering university, this change in emphasis may simply result in collaborative efforts between the physics and engineering departments, and local industry. In a more isolated regional university the supporting engineering college structure often does not exist. This paper discusses the evolution of laboratory experiences in the Engineering Physics program at Murray State University (MSU) involving applications from both mechanical and electrical engineering.

Refinement of the MSU Engineering Physics curriculum and subsequent ABET accreditation illuminated the students' need for applied mechanical and electrical laboratory experiences. In the original physics-based curricula, labs involving mechanical application were practically nonexistent. To provide for new mechanical lab activities, basic laboratory stations were procured, an engineering measurements lab and course were created, and innovative, low-cost practical experiences were developed. These activities quickly became too numerous for a single course, and will need to be distributed into the engineering science courses. The electrical engineering component has been influenced by technology advances and changes in focus. Improvements to laboratory equipment and software have simultaneously simplified many lab measurements while allowing for more complex projects. The focus has shifted from fundamental physics measurements (e.g., an electron's charge) to applied engineering measurements (e.g., a circuit's time constant), and to incorporation of a significant design component. This paper discusses the equipment, software, and design exercises for courses in analog circuits, digital circuits, and mechanical measurements taught within an Engineering Physics curriculum.
\end{abstract}

\section{Introduction}

Physics programs have been in a state of declining enrollment for $\equiv$ yy years. As disheartening as this may be for faculty at research institutions, this trend is evenmore threatening at regional, undergraduate universities where there are no engineering students taking introductory calculusbased physics. There are several reasons for declining enrollment. In the booming economy of the 1980's and 1990's applied engineering became more valued than an in-depth understanding of modern physics, as a product's time-to-market became the driving force in project management. At this same time, major government programs such as the space program, the supercollider project, and the "Star Wars" ABM initiative were in a downturn, while defense spending was affected by the end of the cold war. Primarily because of pressures to broaden 
their curricula, primary and secondary school educators had less success in providing collegebound students with the mathematical tools that would allow them to jump into a calculus-based study of physics. With the increased possibilities provided by the internet, many young people saw themselves trying to cash in on their abilities to write web pages, rather than suffering through a rigorous science curriculum. Now with the outbreak of peace and the threat of bioterrorism, the biological and medical sciences are currently seen as promising careers. With the increased power of modern calculators and computers, many students question the reasons for learning algebra and calculus. All these reasons, and more, have caused faculty in physics departments at smaller institutions to re-evaluate the direction of their programs.

One approach that is being taken to maintain the relevance of the physics department is to change the curriculum into a more applied engineering physics program ${ }^{1,2,3}$. The Engineering Physics major varies significantly from university to university. In universities with established engineering colleges, the Engineering Physics major may be used to attract students who view themselves as both scientists and engineers. In these institutions the program combines the resources of the physics department with several of the engineering departments in a way which provides for a more consistent stream of major students without changing the number of faculty. Other engineering physics programs that are co-located with engineering colleges seek to involve students in high tech applications that traditional engineering curricula can not include. These might include a variety of modern physics applications. In some countries engineering physics is a euphemism for nuclear physics. In these situations where an engineering college is solidly established, development of this new field can occur relatively naturally as a blend between the physics department, the engineering departments and local industry. In more isolated, regional universities, however, the progression toward providing an engineering physics major is more difficult because of the infrastructure that must be developed in order to deliver a viable applied curriculum. This paper addresses one aspect of this challenge: the development of engineering physics laboratories from an exclusively physics department stem.

At Murray State University (MSU), the Engineering Physics major existed for around twenty years before the decision was made to have it accredited. The curriculum was similar to the Physics major, but allowed for a few more applied tracks with specializations in computer applications, mechanics, electronic instrumentation, advanced computational physics, and preprofessional programs. Efew modifications were made to the curriculum to require sufficient design credits, three faculty with engineering backgrounds were hired, and in 1997 the program was accredited by the Accreditation Board for Engineering and Technology / Engineering Accreditation Committee (ABET/EAC). Currently the program is a blend of mechanical and electrical engineering and also requires several higher-level physics courses. Since Electrical/Computer and Mechanical Engineering students make up over half of the engineering undergraduate population nationwide ${ }^{4}$, this is a way to greatly improve student numbers. Although the department owned several extensive research labs including an accelerator, a semiconductor clean room and an $\mathrm{x}$-ray lab, one of the concerns of the program was the availability of student instructional labs. The existing labs had focused more on observing physical phenomena, as opposed to measuring processes and putting them into a design context. As surveys were taken in preparation for the subsequent visit under the ABET 2000 criteria, lab availability was the most prominent concern of $\equiv$ lents and alumni. The goal of improving the student labs became an essential element to assurnng that our graduates would have both 
confidence and competence in real world engineering situations. Therefore, there was consensus among faculty, students, alumni and the administration that the labs needed improvement.

As the program grew, it was clear that the students had pretty evenly divided interests between electrical and mechanical engineering. The existing labs included the research labs, the general physics labs, an advanced physics lab and an electronics and digital lab with some relatively outdated equipment. None of the labs addressed areas that were related to the mechanical engineering topics being taught. First, the issues that were considered when selecting lab equipment will be discussed. Next, the problem of starting a mechanical engineering lab from scratch will be addressed, followed by the experiences that were gained in modernizing the electrical labs.

\section{Considerations in Selecting Engineering Physics Lab Equipment}

The funding for development of the MSU labs became available over a four-year period. In the process of selecting equipment, several competing objectives in the design of the educational labs had to be considered. As the equipment was chosen, installed, interconnected and evaluated, several considerations needed to be made concerning the layout and design of the labs, and the activities that would be undertaken. The very objectives of the laboratory experience had to be considered. Some of the same processes might go into designing the lab space in a new building, but in this case the layout was somewhat restricted to available space in the department. The following are some possible objectives that were considered when choosing the type of equipment for the lab:

a. Plug and play. Because there is only one technician available for all research and teaching labs in the college of science, equipment that had little or no institutional set up and maintenance was preferred.

b. Structured experiments. Although open-ended experiments are more true to life, students are driven by their schedules. They prefer to be told how to conduct experiment and what to look for. They are concerned with organization of the lab and want to be confident that they will be able to obtain meaningful results in a reasonable period of time.

c. Multiple work stations. Equipment that is sufficiently inexpensive to allow for multiple stations is preferable for two reasons. Multiple stations allow students to have access to the laboratory experience as individuals or pairs, requiring greater involvement. The alternative to this might also mean that students would have to cycle through the station, requiring students and faculty to reschedule their work. At MSU the lack of a graduate program and the course pre-requisites make use of an undergraduate lab assistant problematic. The second reason that multiple stations are preferred is to allow for program growth.

d. Connections with faculty research. Ties to current faculty research are a natural plus at research institutions, but are also beneficial at small undergraduate institutions. At these universities research requirements are still important, but time and resources are more restrictive. 
e. Support the classroom theory. Labs should be primarily designed to reinforce what is introduced in the classroom. Although some room for open-ended experimentation is important, the lab activities go more smoothly if the students have a sufficient understanding of the process they are testing. At the same time, lumping most of the lab experience into one course seems to be detrimental as there is no "just in time" learning.

f. Curriculum support. Support for a wide range of the curriculum is desired since future funding for student labs is not assured. This would also allow for moving lab activities into the engineering science courses.

g. Lab documentation. Much of the work involved in setting the lab up involves integrating the lab into the flow of the course. Lab equipment with detailed instructions and lab experiment worksheets eliminate some of the work required by the instructor. However, one difficulty that occurs is that some lab equipment comes with too many possible experiments that rely on going through the whole series. For example, a work station may have seven different displacement transducers and eleven different lab procedures. Since there is only time for perhaps two activities in the curriculum involving this equipment, it may be more difficult to pull a vendor-supplied procedure out of its context than it would be to write an introduction and procedure from scratch. Additionally, labs that are developed overseas sometimes seem to use unusual symbols and nomenclature.

h. Recruiting. It is desired that the equipment have some degree of curb appeal. Labs that would impress prospective students and excite them about the program are a bonus.

i. Support for regional K-12 programs. Because of the regional nature of MSU and because its origins are in public education, equipment that might be used to support secondary school science programs was somewhat favored.

j. Open-ended experimentation. It is important that students develop critical thinking skills that involve making their own decisions on how to run an experiment. One focus of the NSF grant for this project was to provide for inquiry-based experimentation. Although some equipment to provide for this open-ended type approach is important, the major task in the engineering lab was seen to be in providing structure and tools through which engineering knowledge can be applied. This criterion presents a major trade-off between in-depth, student-directed experimentation and providing for an adequate quantity of practical experiences with sufficient breadth.

k. Usability in student projects. The purchase of expensive equipment for perhaps one use in a given year may be wasteful. Since students are required to do projects, it is nice if the measurement equipment supports their other work in design and research.

\section{Development of Mechanical Engineering Laboratories}

Most mechanical engineering departments have extensive laboratory facilities that have been developed through years of grant-funded research. When this equipment is no longer needed for research it becomes available in the teaching labs. In the MSU program, mechanical engineering 
labs beyond the General Physics course mechanics lab had to be developed from scratch. The funding for the lab equipment came primarily from two sources: institution-supplied funding of $\$ 100,000$ resulting from concerns from the initial ABET visit and then a National Science Foundation (NSF) grant which, when matched, also provided for around \$100,000.

In order to provide a level of focus to the development of the laboratories, it was decided to establish a course in Engineering Measurements that included a lab period. This course was designed to be a rounded course that would teach students the basics of measurement technique and familiarize them with a wide variety of measurement equipment. This approach also reflects the interdisciplinary nature of the MSU Engineering Physics major. The course is divided into sections on experimental method and uncertainty, electrical principles (transducer operation, signal conditioning, analog to digital conversion), and mechanical measurements ${ }^{5,6}$. The breadth of this course, which follows the content of several common texts ${ }^{7-10}$, makes it very demanding.

The first step in developing the Engineering Measurements lab was to procure some basic work stations. Four stations were procured from Feedback, Inc. for studying displacement, temperature, and optical transducers. These analog stations made use of common electrical instruments. Since the space available for the lab was a portioned-off section of the Circuits lab, these stations with their complete user manuals could be used immediately. Five stations were outfitted with computers, inexpensive data acquisition cards, National Instruments' LabVIEW software and other common transducers (differential pressure cell, accelerometer, microphones and speakers). These stations provided flexibility in deciding which experiments to use and helped students take measurements from the sensor to data analysis in discrete steps. One station was placed on a cart so that it could be used later in the mechanical lab area.

With a host of basic sensors and sufficient equipment to record and analyze the data, the next step was to find mechanical phenomena to test. Several low-cost experiments were made to fill this need, and at the same time provide the students with opportunity to create experiments to answer their questions. Figure 1 shows some of the labs that the students developed. Initially, the department had no wind tunnel or flow chambers to test fluid flow, so the students learned about u-tube manometers and Pitot-static tubes by creating a window cover and testing the speed

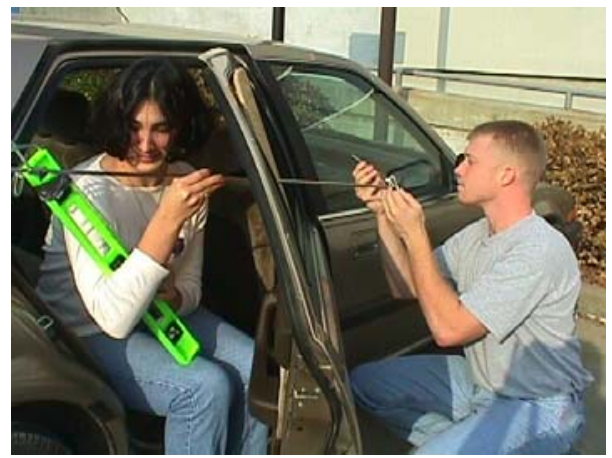

(a)

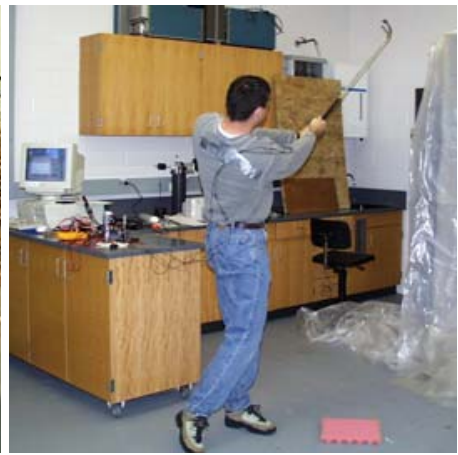

(b)

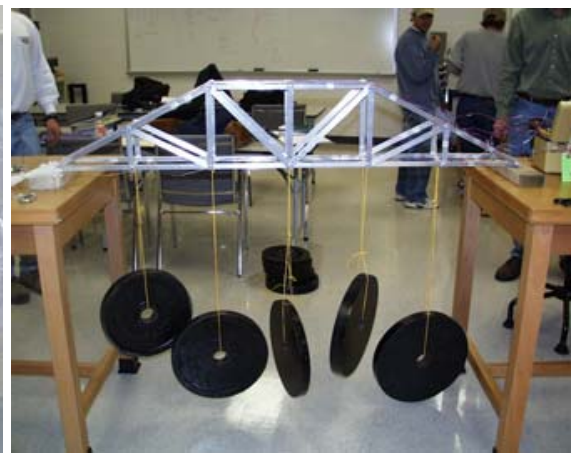

(c)

Figure 1. Low-cost mechanical labs: (a) air velocity lab, (b) strain gage golf club lab, (c) strain gage truss loading lab

and velocity profile outside of a car. In the lab for studying strain gages, students were asked to bring in their own object to test. Students tested the strain on a golf club and determined its 
natural frequency, examined the stresses on a coke can, and determined the stress on a bicycle pedal. Many additional low-cost experiments can be found in Ref. 11. In another activity, the instructor created a truss of aluminum members. Each student applied a strain gage to one of the members and analyzed various loads on the truss. This particular experiment reaches deeply into the curriculum through the analysis of loads on trusses and the evaluation of stresses and buckling.

After the lab stations were in place and operating the next priority for available funds was to provide for some uniquely mechanical experiments. Since support for the Materials Science course and the Mechanics of Materials courses would eventually be needed, some basic materials testing equipment was procured. The devices are a tensile and Brinell hardness tester, a Charpy $\mathrm{V}$-notch impact tester, a furnace for heat testing, a fatigue tester, and a twist and bend apparatus. Although these devices are not research grade, the combined cost was equivalent to a single tensile test apparatus. It seemed reasonable to pursue this low-cost route since the number of uses per year would be low and this field was not a research area of any of the faculty. Generally these devices get used for an independent experimentation project in the Engineering Measurements course, and occasionally for individual research projects. Along with the materials science equipment, equipment from Vishay Measurements Group was procured for examining simple bending tests and for providing simple testing using strain gages. This equipment provide the easiest experiments to run in the course because the strain gage instrument and the switch and balance unit are reliable, and because the gauged beams for determining Young's modulus, Poisson's ratio, and stress concentrations are professionally made. The only down side is that only one unit was purchased. The experiments are relatively short and three or four groups can usually cycle through a few experiments during the two-hour lab period. As the program matures, it is likely that these devices will be incorporated into the Materials Science and Mechanics of Materials courses.

After acquisition of the new materials and strain gage equipment, the remaining area in the mechanical labs was fluid mechanics. Equipment from this lab was procured through the NSF grant and institutional matching funds. Figures 2 and 3 highlight the big ticket items from this grant, which were an Aerolab Educational Wind Tunnel and an ELD Flow Visualization Water Tunnel. Procedures and models for several straight-forward labs are provided with both tunnels. Additionally, the tunnels have been used in an inquiry-based investigation of the flight of baseballs and Frisbees. A manometer was built at low cost to evaluate pressures at different points along various models. A system to measure 24 differential pressures simultaneously is also being constructed to investigate some flow dynamics around objects and to provide for faster experimentation and more student interaction.

A unique solution to providing for testing of internal flows and open channel flows was to design and build a fluid friction device. The device contains tubing sizes that will allow for laminar and turbulent flows, investigation of minor losses across four different types of valves and an elbow, water and electronic manometers and five different flow measuring devices. Since the system was designed in-house and built using student labor over one summer, the net cost of \$6000 including labor was roughly one-fourth of other commercial units that do not contain flow sensors or an electronic manometer. 

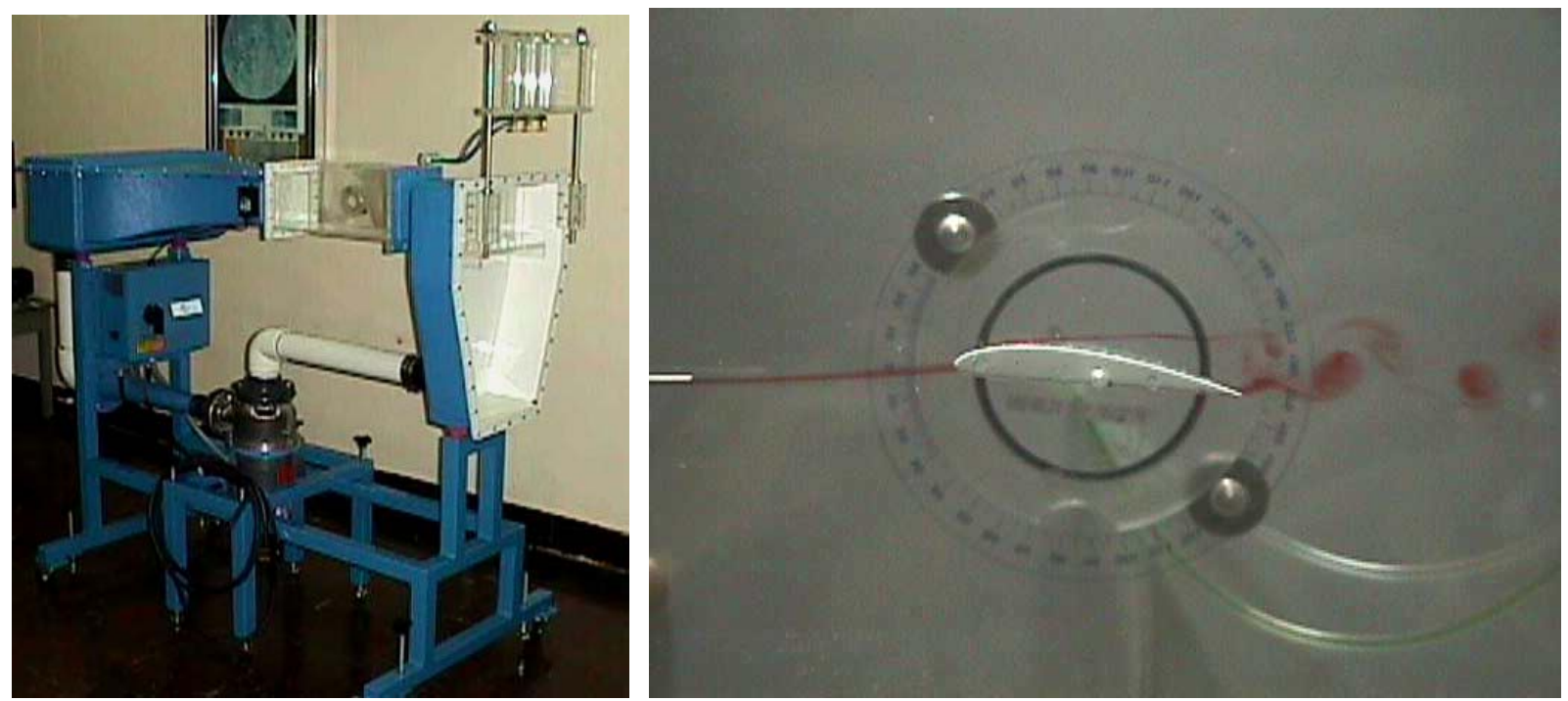

Figure 2. ELD Educational Water Tunnel and view of tunnel section in use
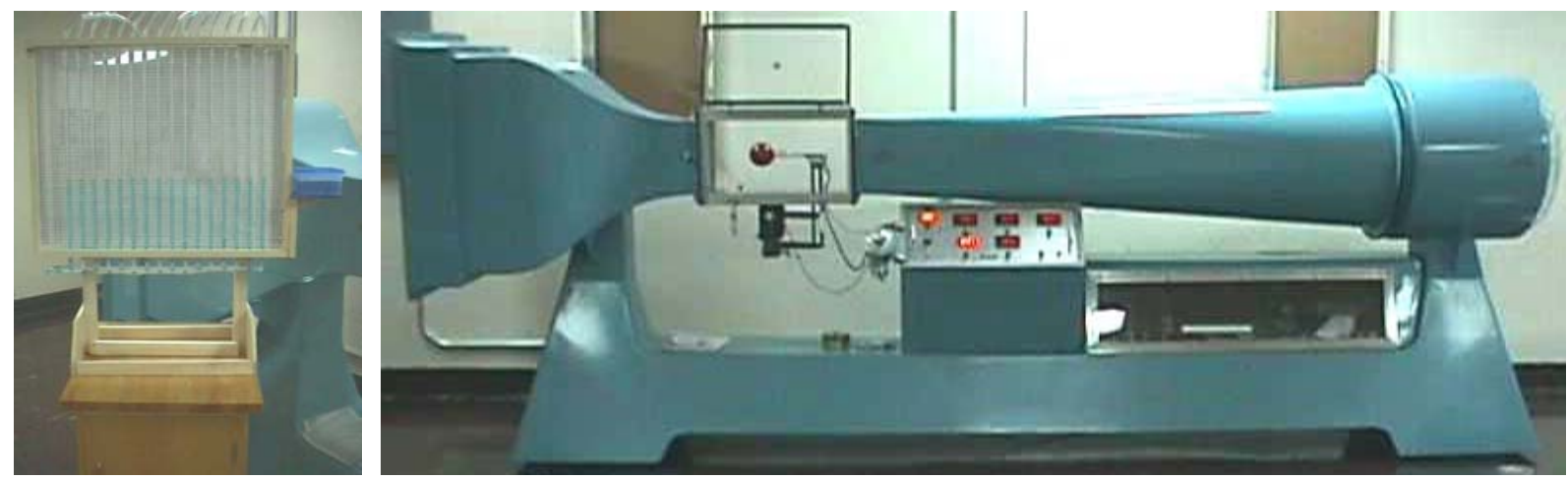

Figure 3. Multi-tube manometer and Aerolab Education Wind Tunnel

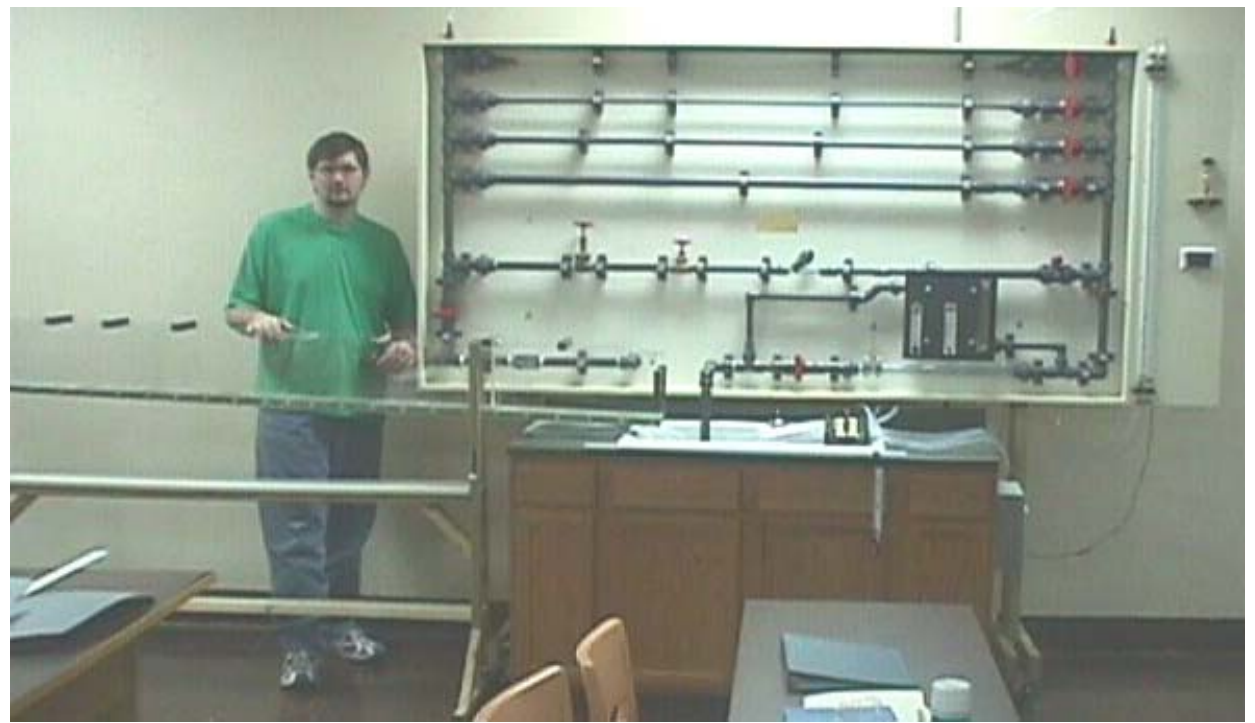

Figure 4. Fluid Friction Apparatus 
Another aspect of the NSF grant work involved using students to develop small-scale fluid mechanics lab devices that could be extended into the secondary school science curriculum. In the first part of this work a student designed and constructed three apparatuses to show basic fluid mechanics principles. The first one demonstrated the basic concept of pressure using Pascal's principle by connecting a ball pump and a child medicine syringe with tubing and creating a hydraulic balance. The second investigated the idea of fluid energy through Torricelli's principle by measuring the distance traveled by a jet of water coming from a water cooler, as a function of the height of water in the cooler. The last one used the cooler, a reducing tee, and Tygon tubing to show Bernoulli's principle by measuring the pressure in a region of reduced flow area. These devices could easily be purchased for less than thirty dollars and constructed in a few hours.

Along with activities that could be constructed and used by secondary school teachers, additional labs were developed by students that could be used both in the fluid mechanics course and as traveling demonstrations to motivate secondary school students toward careers in science and

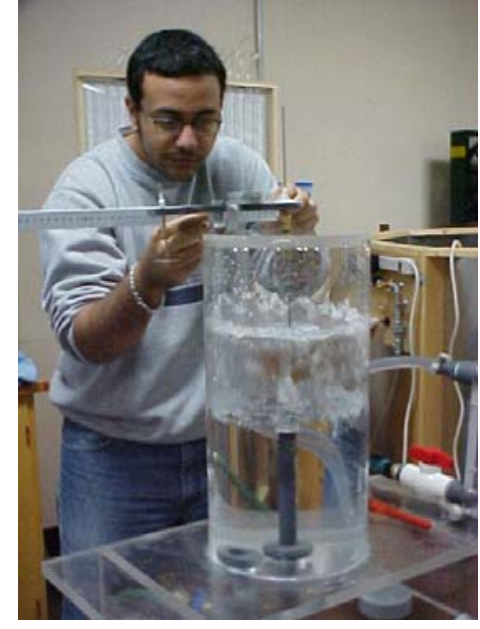

(a)

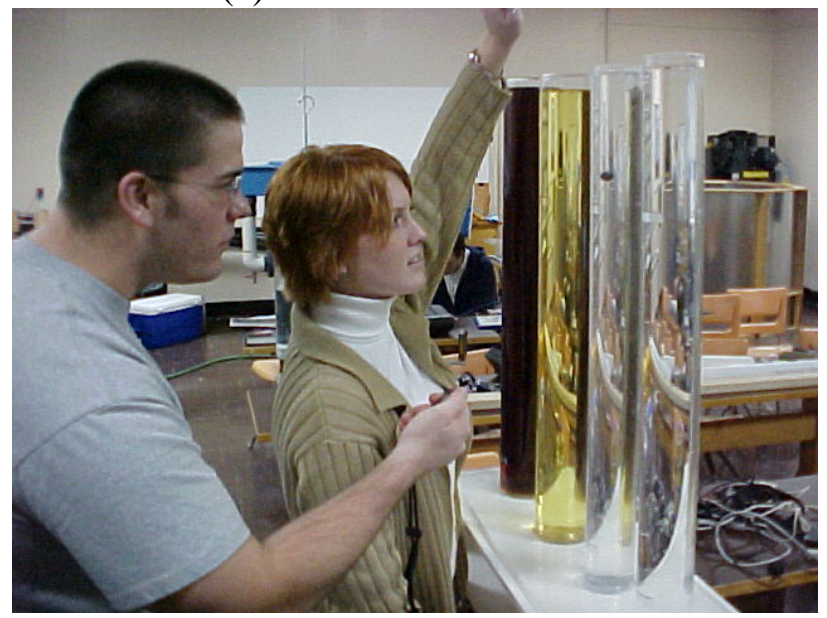

(c)

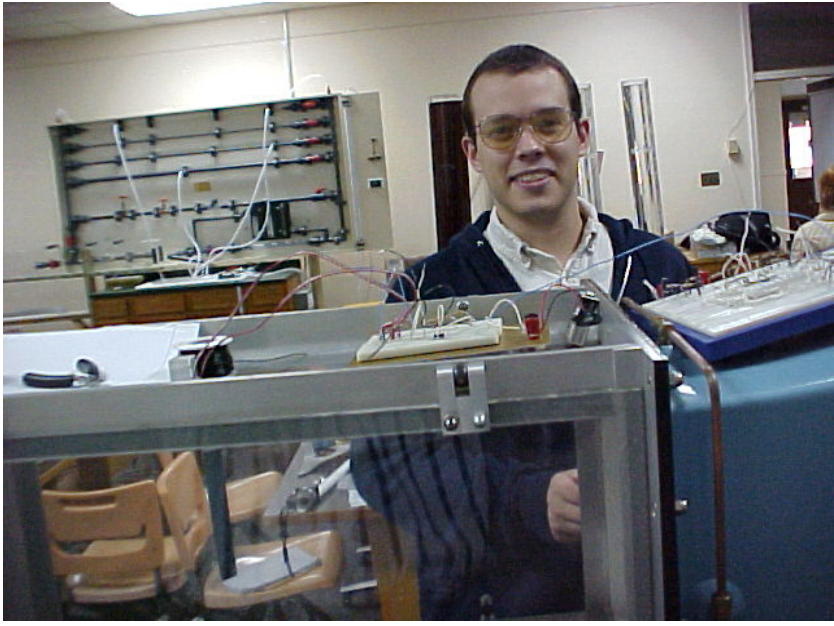

(b)

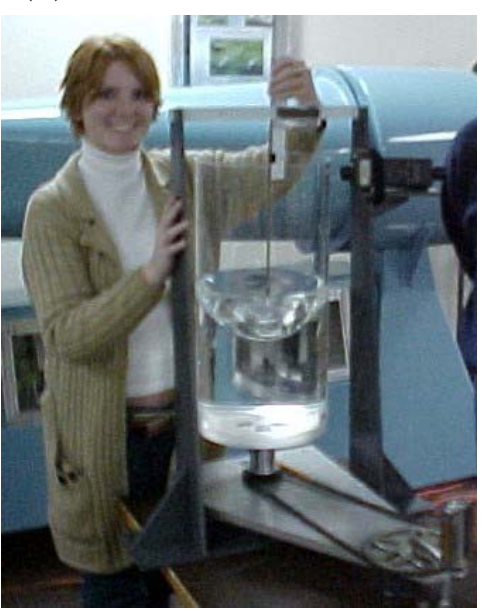

(d)

Figure 5. Student-developed lab apparatuses. (a) Impact of Jets, (b) Vortex-Shedding Flow Meter, (c) Stokes Law Viscometer, (d) Rigid-Body Rotation of Fluids 
technology. To create these activities, four students taking the Engineering Measurements course jointly designed and built these devices with departmental staff, and then performed tests on them as their assigned individual experimentation project. Reference 12 discusses how ownership of the experiment can lead to better experimental design. This seemed to be a byproduct of this activity. The projects consisted of an impact-of-jets device that validated fluid momentum equations, a vortex-shedding flow meter that was designed to be used in both the water and wind tunnels, a Stokes law viscometer that used four fluids of widely varying viscosity, and a solid body rotation device that validated the parabolic shape of the fluid surface. These devices were slightly more expensive, costing between $\$ 100$ and \$300, but were considered by each student to be the highlight of the Engineering Measurements course. They can also be used for short lab demonstrations if time for longer experiments is not available. This type of activity is discussed in Ref. 13.

The development of mechanical engineering labs accomplished most of the objectives that were established for it. By beginning with an Engineering Measurements course and expanding from it into each discipline of mechanical engineering, students have a much more hands-on learning experience than was formerly available. The most significant aspects of this approach are its breadth of activity, student involvement, and attractiveness to new students. The objectives that need more emphasis are improving the lab documentation and reducing the significant requirements for equipment upkeep and setup. Because of the number of activities developed, the curriculum also needs to be revised to incorporate some of these activities into other courses.

\section{Development of Electrical Engineering Laboratories}

Unlike the mechanical lab exercises described in Section 3, Murray State has always had some basic electrical labs in its Physics and Engineering Physics program. However, the content and purpose of the labs has changed greatly over the past two years. This modification of the electrical engineering laboratory component of the Engineering Physics curriculum has been influenced by two major factors: (1) A change in focus from fundamental physics labs to more applied engineering measurements and (2) major technological advances in software and hardware tools. The two factors will be discussed in more detail, as well as how they affect lab assignments in an analog circuits course and a digital logic course.

\subsection{Focus shift from physics to applied engineering}

When electrical laboratories are taught for Physics majors (or by Physics Ph.D.s) they will generally be focused on understanding and measuring basic physical phenomena. For example, at Murray State University in the 1960's and 1970's, the students performed lab exercises to measure the charge on the electron (similar to the Milliken oil drop experiment) and measure the charge/mass ratio of the electron. As the electrical laboratories have developed into an Engineering Physics program, with more emphasis on Engineering and less emphasis on Physics, the lab exercises have focused on more practical (some would argue more mundane) goals such as (a) how to use simulation software and lab instrumentation, (b) how to design electrical circuits, (c) how to debug a circuit and determine why it is not working ("learn from failure"), 
(d) how to verify the applicability of a particular model (e.g., Thevenin's equivalent) and (e) how to analyze experimental data. (These goals are in agreement with the laboratory learning objectives outlined by Feisel and Peterson. ${ }^{14}$ ) Note that model verification is the only goal that overlaps with the "fundamental physics" focus. Thus the focus of the hands-on portion of the curriculum has changed considerably.

\subsection{Technology changes}

Recent technology advances necessitate a major adjustment in the electrical lab exercises. The technology advances affect the lab exercises in three ways. The first affect is new devices. This is most apparent in the digital world since design using multiple small-scale integration devices has been replaced with single devices such as Application Specific Integrated Circuits (ASICs) and Field Programmable Gate Arrays (FPGAs). In addition, faster and more specialized microprocessors and Digital Signal Processing chips impact more advanced digital lab exercises.

The second affect is better test equipment, such as digital oscilloscopes, high frequency function generators, logic analyzers, and spectrum analyzers. Since one of the program's objectives is to teach students to "use appropriate sensors, instrumentation, and/or software tools to make measurements of physical quantities" 14 then there is a need to teach them the difference between the various instruments and how to use them. For example, since many students have never used an oscilloscope before taking the circuits lab they may not appreciate the advantages of a digital scope over an analog scope. However, the learning curve is slightly longer for the digital scope since there are more features (e.g., delayed sweep, automatic measurements, averaging, zoom, on-screen markers).

The third affect of technology advances is better software programs. Clearly, general-purpose programs like Excel make the analysis and presentation of data much easier and time efficient than "hand" calculations. However, faster computers have led to more sophisticated circuit analysis and simulation programs. An earlier generation of students learned pspice but that has now been incorporated into more sophisticated packages such as MultiSim/Electronics Workbench. In addition, software programs such as Mathematica, MathCAD and Matlab simplify the data analysis. (At Murray State, the mechanical courses use MathCAD and the electrical courses use Matlab.) And there are programs by companies such as Xilinx to handle the mapping and configuration of circuits onto FPGAs. The software programs allow the students to tackle more ambitious design projects since the theoretical calculations can be automated and the circuit can be simulated before the time-consuming "build phase".

\subsection{Structure of electrical lab courses}

Murray State recently upgraded the equipment in its analog and digital circuits labs to give the students exposure to modern tools and to incorporate electrical design concepts. In selecting the new electrical equipment, the department used the same considerations described in section 2 .

For the analog circuits lab each of the 8 lab stations now consists of a "test suite" containing

- AGILENT E3631A Triple output DC power supply

- AGILENT 33120A 15 MHz Function Generator 
- AGILENT 34401A Digital Multimeter

- AGILENT 54622A $100 \mathrm{MHz}$ Digital Oscilloscope

- PC $-1.6 \mathrm{GHz}$ clock speed, 256 Mbytes RAM

- ETS-700 Multifunction prototype board

The total cost of the test suite (minus the computer) is about $\$ 5500$ (Fig. 6). The computer is not essential for an introductory circuits lab. However, it can be used to run the circuit simulation software (MultiSim) and data analysis software (Matlab). It is also useful for more advanced labs/courses for automated data acquisition projects.

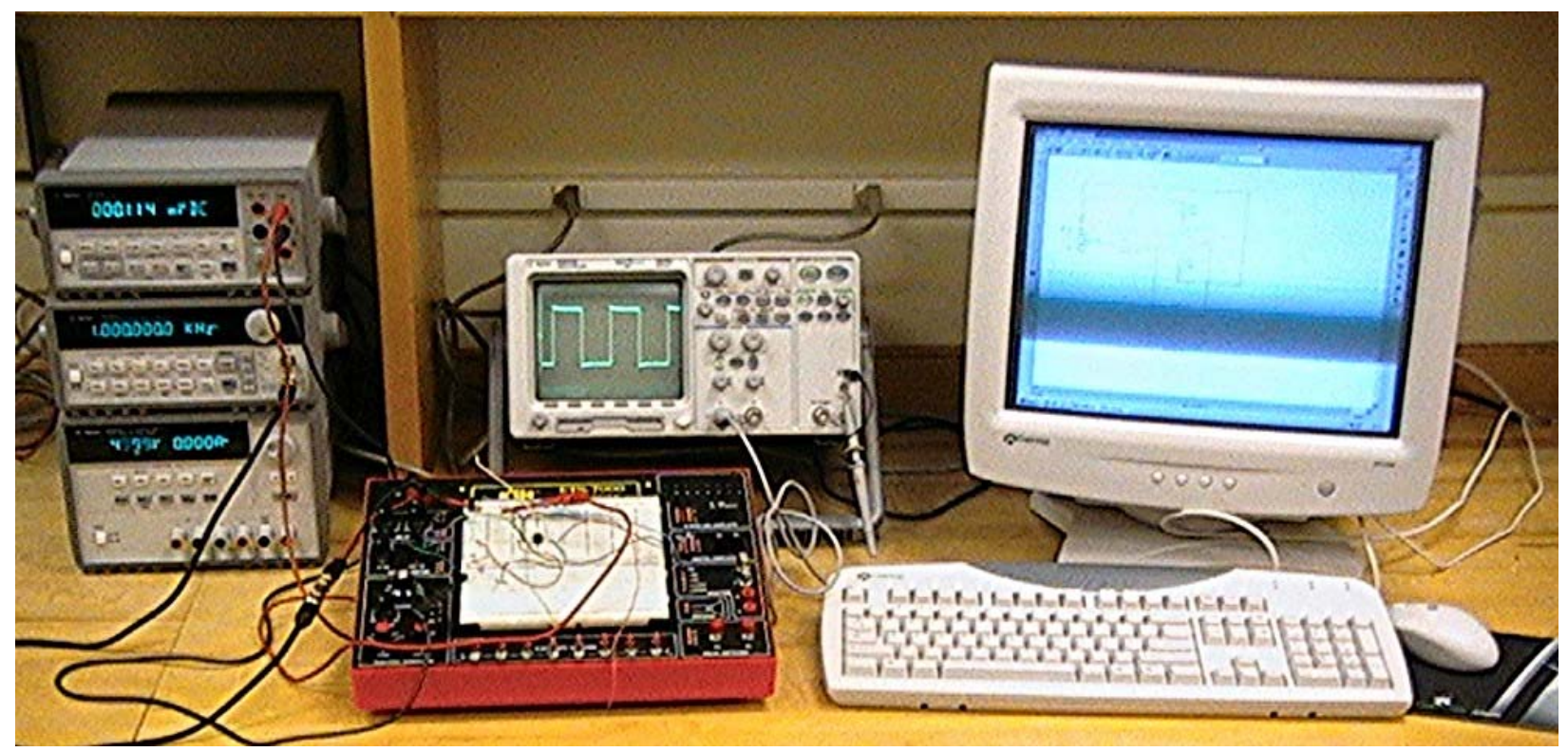

Figure 6. Lab station for newly revised circuits lab

The digital logic lab utilizes

- Basic protoboard

- Digilab XLA5 board with Xilinx FPGA chip

- Xilinx Integrated Software Environment (ISE) software (required to use the FPGA boards)

The Digilab FPGA boards were donated to Murray State by the Xilinx University Program. The software came with the textbook but can be purchased for about $\$ 90 /$ copy. Thus, there is very little expense in equipping the lab. A useful device, that we do not presently have, is a logic analyzer.

To adjust the focus of the electrical labs with its EP curriculum, Murray State University has overhauled the content of the analog circuits labs and the digital logic labs over the past two years. Lists of the major assignments in each lab are shown in Table 1 and Table 2. 


\begin{tabular}{|l|l|}
\hline Lab Title & Brief Description \\
\hline Introduction to oscilloscope & $\begin{array}{l}\text { A quick-start to what a digital scope does and some of } \\
\text { its features. Completely self-contained lab that can be } \\
\text { completed with almost no knowledge of circuits. }\end{array}$ \\
\hline $\begin{array}{l}\text { Resistance, voltage and frequency } \\
\text { measurements }\end{array}$ & $\begin{array}{l}\text { Learn proper use of lab instruments and correct method } \\
\text { for measuring voltage, current, resistance, etc. Get } \\
\text { acquainted with function generator, power supply, } \\
\text { multimeter. }\end{array}$ \\
\hline Principle of superposition & $\begin{array}{l}\text { Show the total output can be determined by summing } \\
\text { the output from individual sources. Includes simulation } \\
\text { component. }\end{array}$ \\
\hline Thevenin equivalent circuits & $\begin{array}{l}\text { Derive Thevenin equivalent for a circuit and show it } \\
\text { supplies same voltage to a load resistor }\end{array}$ \\
\hline Introduction to op amps & $\begin{array}{l}\text { Build } 3 \text { op amp circuits: inverting amplifier, non- } \\
\text { inverting amplifier, integrator }\end{array}$ \\
\hline Exponential waveforms & Observe step response and measure RC time constant \\
\hline Impedance & $\begin{array}{l}\text { Design a circuit to meet specified step response } \\
\text { parameters. } 1^{\text {st }} \text { design lab. Includes simulation } \\
\text { component. }\end{array}$ \\
\hline Active filter response & $\begin{array}{l}\text { Measure, and plot, the impedance at multiple } \\
\text { frequencies for a resistor, capacitor, and inductor }\end{array}$ \\
\hline $\begin{array}{l}\text { Analyze the performance of op amp circuits in the } \\
\text { frequency domain and introduce active filters }\end{array}$ \\
\hline $\begin{array}{l}\text { Design a bass volume control circuit and a treble } \\
\text { volume control circuit. (Basically, design an active } \\
\text { lowpass circuit and active highpass circuit.). Major } \\
\text { design project. Includes simulation component. }\end{array}$ \\
\hline
\end{tabular}

Table 1: List of assignments in analog circuits course

\begin{tabular}{|l|l|l|}
\hline Lab title & Brief description & Comment \\
\hline $\begin{array}{l}\text { Message on 7- } \\
\text { segment display }\end{array}$ & $\begin{array}{l}\text { Write a simple message } \\
\text { (about 6 to 8 characters) on a } \\
\text { 7-segment display }\end{array}$ & $\begin{array}{l}\text { Requires only knowledge of } \\
\text { combinational design techniques. } \\
\text { Gives students exposure to building } \\
\text { circuits from simple SSI gates. }\end{array}$ \\
\hline $\begin{array}{l}\text { Combinational } \\
\text { circuit simulation }\end{array}$ & $\begin{array}{l}\text { Use schematic capture and } \\
\text { simulation tools to simulate a } \\
\text { simple combinational circuit. }\end{array}$ & $\begin{array}{l}\text { First exposure to Xilinx digital } \\
\text { software tools that will be used for } \\
\text { FPGA labs and projects. }\end{array}$ \\
\hline Binary counter & $\begin{array}{l}\text { Implement a 3-bit counter on } \\
\text { an FPGA }\end{array}$ & $\begin{array}{l}\text { Simple sequential design. First } \\
\text { exposure to FPGA hardware tools. }\end{array}$ \\
\hline Blackjack & $\begin{array}{l}\text { Build a circuit that plays a } \\
\text { simplified game of blackjack } \\
\text { that uses only Aces, Fives } \\
\text { and Tens. }\end{array}$ & $\begin{array}{l}\text { Multi-week design project. Good } \\
\text { project because there are several } \\
\text { possible design approaches and it is } \\
\text { "fun”. }\end{array}$ \\
\hline
\end{tabular}

Table 2: Overview of digital logic lab assignments 
Specifically, lab assignments were selected and written to

a) introduce the lab equipment and special-purpose software (digital scope, function generator, multimeter, MultiSim, etc)

b) allow students to design a component and test it,

c) verify theoretical models,

d) do data analysis.

Many of the analog lab assignments were based on pre-written assignments available on the Agilent web site. See www.educatorscorner.com.

Since one of our objectives is to allow students to design electrical components, instead of just analyze circuits, there are two assignments in each lab course devoted to design. In the analog circuits course, the students are asked to design a circuit that is similar to one that they have seen previously. They must recognize what type of circuit they should use and then pick appropriate component values. In the digital logic course, on the other hand, specific design steps are spelled out during the semester. The digital design assignments can thus be relatively complex and something far different than anything else that they have seen.

\subsection{General results of electrical lab development}

Many of the labs would not have been possible even 5 years ago since the tools had not been fully developed (FPGA) or the instrumentation would have been extraordinarily expensive (e.g., digital oscilloscope and function generator). A major benefit of the new tools is that less time in lab doing "grunt” work (taking data, plotting curves) and more time doing design and analysis. Thus, there is more time spent doing complex projects such as the blackjack game and the 2-channel stereo equalizer. This increases the students' interest level and helps relate the classroom material to real-world applications.

The new hardware and software tools do make lab exercises easier in many ways and lead to more productive lab time. However, there are a couple of drawbacks. First, upgrading every time there is a new product on the market can be expensive. The new test suite (digital scope, function generator, power supply, and multimeter) for the circuits lab cost about $\$ 5,500$ per test suite (with educational discount). Likewise, the software companies usually offer student edition versions or steep discounts for academic use (in the case of Matlab, the cost is less than 1/50 of the regular commercial license cost) but when outfitting a lab of 10 or 20 computers the cumulative price can be large. The second drawback is the preparation time involved in learning new tools and writing new assignments to take advantage of the new tools. For example, Xilinx releases new versions of its FPGA chips and software programs every couple of years. The latest release would not read circuits saved using the old release so all lab exercises had to be redone. In addition, the user interface and design/simulation steps had been changed significantly.

Also, the improved software programs are certainly helpful and reduce the time on mundane theoretical calculations. However, as with the improved test equipment, there is a slight downside in that some time must be spent teaching the students how to use the software. In some (rare) cases, software bugs and/or difficulties have actually delayed student learning and 
led to an overall frustration with the course material. Students spend more time just learning the software steps and less time learning the electrical concepts.

\section{Future Direction and Conclusions}

While most of the infrastructure in the metamorphosis in the MSU Engineering Physics program laboratories has been laid, much remains to be done. A critical element is the development of a lab manual for the experiments that more completely connects the activities to the curriculum and also documents procedures for lab assistants to help with the conduct of the labs. Additionally, there are now too many possible mechanical lab activities to conduct in the engineering measurements course. With the large number of fluid mechanics activities, a natural transition will be to add a lab component to the fluid mechanics course. Another significant change in the program is the addition of a new Electrical and Telecommunications major at MSU. While funding for this program has not been firmly established, new laboratory courses for this curriculum are being developed. Finally, there is some risk of losing the physics identity during this change. To prevent this, a search for a pure physicist with some experimental background is underway to replace a retiring faculty member.

The evolution of a traditional physics program into an engineering physics program requires significant changes to laboratory activities. These changes must meet the objectives demanded by new, more active learning styles. They are necessary due to the development of new directions in the curriculum and to keep pace with changing technology. At MSU the foundation of this change required conversion of two classrooms into laboratory space for the mechanical labs, and a complete change in equipment for the electrical labs. Use of computers in these labs has eliminated some of the tedious detail, allowing students to more thoroughly experiment and perform data analysis. The changes to date have required considerable cost and effort, but these and continued improvements provide for enhanced student learning opportunities.

\section{Acknowledgements}

The development of the hydro-mechanical laboratories was supported by National Science Foundation grant DUE-9952403. The support of NSF is greatly appreciated.

\section{References}

1. H. T. Evensen, "Metamorphysics: Changing to EP at UW-Platteville”, Proceedings of the 2002 Annual ASEE Conference and Exhibition, June, 2002.

2. D. K. Probst, “A Proposed Interdisciplinary Capstone Course”, Proceedings of the 2002 Annual ASEE Conference and Exhibition, June, 2002.

3. S. H. Cobb, J. Crofton, S. R. Hickman, W. E. Maddox, and T. D. Thiede, "Design Considerations in Engineering Physics: Integrating Design Across the Curriculum," Proceedings of the 2000 Annual ASEE Conference and Exhibition, June, 2000.

4. "Engineering Education by the Numbers", ASEE Profiles of Engineering and Engineering Technology Colleges, 2001 Edition (See www.asee.org)

5. W. D. St. John, “A Laboratory Course in Sensors”, Proceedings of the 2001 Annual ASEE Conference and Exhibition, June, 2001. 
6. H. Sumali, "An Instrumentation and Data Acquisition Course at Purdue University", Proceedings of the 2002 Annual ASEE Conference and Exhibition, June, 2002.

7. R. S. Figliola and Beasley, D. E., Theory and Design of Mechanical Measurements, $3^{\text {rd }}$ Ed. John Wiley and Sons, New York, 2000.

8. J. P. Holman, Experimental Methods for Engineers, $7^{\text {th }}$ Ed. McGraw-Hill, New York, 2001.

9. T. G. Beckwith, Marangoni, R. D., and Lienhard, J. H., Mechanical Measurements, $5^{\text {th }}$ Ed. Addison-Wesley, New York, 1993.

10. A. J. Wheeler and Ganji, A. R., Introduction to Engineering Experimentation, Prentice Hall, 1996.

11. Experimental Stress Analysis Notebook, Vishay Measurements Group, Inc., Regular issues from October 1985. ( www.vishay.com/brands/measurements_group/schools/nbli.htm)

12. R. J. Robinson, "Improving Design of Experiment Skills through a Project-Based Fluids Laboratory", Proceedings of the 2002 Annual ASEE Conference and Exhibition, June, 2002.

13. S. M. Kresta, "Hands-on Demonstrations: An Alternative to Full Scale Lab Experiments", Journal of Engineering Education, 87, 1, January 1998.

14. L. D. Feisel and G. D. Peterson, "A Colloquy on Learning Objectives for Engineering Education Laboratories", Proceedings of the 2002 ASEE Annual ASEE Conference and Exhibition, June 2002. 